\title{
Optical and Electrical Properties of Highly Doped ZnO:Al Films Deposited by Atomic Layer Deposition on Si Substrates in Visible and Near Infrared Region
}

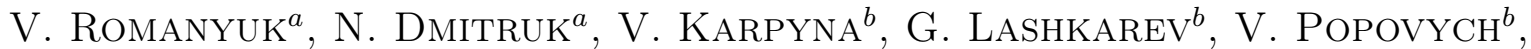 \\ M. Dranchuk ${ }^{b, *}$, R. Pietruszka ${ }^{c}$, M. Godlewski $^{c}$, G. Dovbeshio ${ }^{d}$, I. Timofeeva ${ }^{b}$, \\ O. Kondratenko ${ }^{a}, \mathrm{M}$. TABorskA ${ }^{a}$, And A. IEvtushenkO ${ }^{b}$ \\ ${ }^{a}$ Institute of Semiconductor Physics, NASU, prosp. Nauky 45, Kyiv, Ukraine \\ ${ }^{b}$ Institute for Problems of Material Science, NASU, Krzhizhanovskogo 3, Kyiv, Ukraine \\ ${ }^{c}$ Institute of Physics, PAS, al. Lotników 32/46, 02-668 Warsaw, Poland \\ ${ }^{d}$ Institute of Physics, NASU, prosp. Nauky 46, Kyiv, Ukraine

\begin{abstract}
Optical properties of $\mathrm{ZnO}$ films doped by $\mathrm{Al}$ in the range 0.5 to 7 at.\% and deposited by atomic layer deposition were studied in visible and infrared spectral range. Spectral dependences of film optical permittivity were modeled with the Lorentz-Drude approximation resulting in $\mathrm{ZnO}$ :Al plasma frequency and plasma damping parameters. We observed changing electron effective mass from $0.29 m_{0}$ to $0.5 m_{0}$ with increasing electron concentration in the range $(0.9-4) \times 10^{20}$ due to the phenomenon of conduction band non-parabolicity. Comparing the results of optical and electrical investigations we can see that the main scattering mechanism is the scattering on grain boundaries (its contribution is about $60 \%$ ).
\end{abstract}

DOI: 10.12693 /APhysPolA.129.A-36

PACS: 78.66.Hf, 73.61.Ga

\section{Introduction}

Today transparent conductive oxides (TCO) are materials of the great importance for development of "transparent electronics" and photovoltaics, irreplaceable for flat panel displays and thin film solar cells. Zinc oxide doped with III-group elements is one of extensively studied non-expensive TCO materials for indium-tinoxide (ITO) substitution [1].

High electrical conductivity $\sigma$ can be achieved by increasing electron concentration $N$ and maximizing their mobility $\mu$. However, carrier mobility in polycrystalline films is restricted to values $10-40 \mathrm{~cm}^{2} /(\mathrm{V} \mathrm{s})$, lowering at the increase of doping level because of enhanced scattering by ionized donors and their complexes with structural defects. High electron concentrations lead to increased IR absorption and can diminish solar cells efficiency [2].

Electrical and optical properties of weakly doped $\mathrm{ZnO}$ films are widely known [3, 4]. But there is a lack of information about such optical parameters as optical mobility, plasma frequency and electron effective mass for highly doped $\mathrm{ZnO}: \mathrm{Al}$ films from optical measurements of reflectance in visible and near IR wavelength range accompanied with electrical measurements. The effective mass of electrons is the main parameter determining electrical and optical behavior of TCO materials. Thus, knowledge about electrons effective mass is necessary to describe

*corresponding author; e-mail: mykdra@gmail.com carrier transport in degenerated semiconductors. Recently, the effect of non-parabolicity of conduction band on transport phenomena in $n$-type $\mathrm{ZnO}$ was reported in [5]. Using the analytical equation for $m^{*}$ vs. electron concentration proposed by Ellmer [6] there was demonstrated a good correlation of experimental magnitudes of effective mass, determined by method of four coefficients, and plasma frequency with theory. Optical modeling of free electron behavior was reported by Ruske et al. in [7]. They described the non-parabolicity effect in terms of the Pisarkiewicz approach, but there was no good agreement between theory and experiment. A novel method for determining the electron effective mass and scattering time of $\mathrm{ZnO}$ films with different carrier concentrations was proposed in [8] by combining terahertz time-domain spectroscopy with the Hall measurements. They found that electron effective mass varied from $0.23 \mathrm{~m}_{0}$ to $0.26 \mathrm{~m}_{0}$ as the electron concentration changes from $5.9 \times 10^{17} \mathrm{~cm}^{-3}$ to $4.0 \times 10^{19} \mathrm{~cm}^{-3}$. The non-parabolicity effect was observed for Ga-doped $\mathrm{ZnO}$ films in which effective mass of electron increases up to $0.4-0.46 m_{0}$ at high carrier concentration as $\approx 10^{21} \mathrm{~cm}^{-3}[9]$. In this paper we describe the structural, optical and electrical properties of thin $\mathrm{Al}$-doped $\mathrm{ZnO}$ films deposited on silicon substrates by atomic layer deposition (ALD) process.

\section{Experimental details}

$\mathrm{Al}$-doped $\mathrm{ZnO}$ films with $\mathrm{Al}$ content in the range of $0.5-7$ at.\% and thicknesses in the range of $260-420 \mathrm{~nm}$ were deposited by ALD process on Si substrates. ALD is the kind of chemical vapor deposition (CVD) techniques 
allowing alternatively an introduction of precursors in a vacuum chamber for monolayer growth per cycle. Zinc acetate and aluminum acetate were used as metal precursors and water vapor as oxygen precursor. Substrate temperature was maintained at $160{ }^{\circ} \mathrm{C}$.

The structural parameters were investigated by X-ray diffraction (XRD) using DRON-4 diffractometer, utilizing $\mathrm{Cu} K_{\alpha}$ radiation $(\lambda=0.1542 \mathrm{~nm})$ in conventional Bregg-Brentano $\theta-2 \theta$ geometry. Optical measurements were performed in the 360-1100 $\mathrm{nm}$ wavelength range with a DMR-4 spectrophotometer equipped with incandescent lamp as a light source. Reflectance spectra $R_{\mathrm{p}}(\lambda)$ were recorded for $p$-polarized light at several angles of light incidence. The beam spot diameter on the sample surface was about $3 \mathrm{~mm}$. Infra-red (IR) reflectance spectra in the range $2.0-25 \mu \mathrm{m}\left(5000-400 \mathrm{~cm}^{1}\right)$ were measured with Bruker IFS-66 Fourier-transform spectrophotometer equipped with IPO-22 reflectance attachment at fixed (near-normal, 16.5 ${ }^{\circ}$ ) angle of light incidence. The structure and optical properties were investigated for all as-grown films at room temperature.

Complex dielectric permittivity $\varepsilon=\varepsilon^{\prime}+\mathrm{i} \varepsilon^{\prime \prime}(\varepsilon \prime=$ $\operatorname{Re}(\varepsilon)=n^{2}-k^{2}, \varepsilon^{\prime \prime}=\operatorname{Im}(\varepsilon)=2 n k$, where $n$ is the refractive index and $k$ is the extinction coefficient) of the $\mathrm{ZnO}$ :Al films were obtained from the fitting of measured reflectance spectra with calculated ones using $2 \times 2$ matrix formalism for a "homogeneous isotropic film on the substrate" structure. The dependence of the complex dielectric permittivity on the wavelength in the spectral range of interest was approximated by using the LorentzDrude model.

\section{Results and discussion}

The XRD analysis was performed for all deposited samples. Typical XRD pattern is shown in Fig. 1a where one can see reflexes at peak positions near 31.8, 34.0, 36.0 and $56.72 \theta$ degrees which correspond to reflections from (100), (002), and (110) planes of hexagonal $\mathrm{ZnO}$ lattice. The intense reflexes from (100) and (110) planes accompanied with a small broad line of (002) reflex demonstrate that $c$-axis of the majority of crystallites lies in the film plane. Thus we observed $a$-axis growth mode. It is an unusual situation because film growth as a rule occurs in the direction which has a lowest surface free energy. For $\mathrm{ZnO}$ (002) plane free surface energy is the lowest one $\left(1.6 \mathrm{~J} / \mathrm{m}^{2}\right)$ compared to $2 \mathrm{~J} / \mathrm{m}^{2}$ for (110) plane and $3.4 \mathrm{~J} / \mathrm{m}^{2}$ for (100) plane [10]. As stated in [11] the growth of $\mathrm{ZnO}$ films depends on the substrate temperature and a purging time. The purging time is the time separation between purging the first precursor and inlet second precursor into reactor chamber. In the case of samples deposited with short purging times, the $a$-growth mode is observed at low substrate temperature. We suppose that it can be explained by slow deposition rate at which the surface wettability plays significant role in forming preferred orientation. The presence of water adsorbed on the surface of growing film at purging time can change surface energy and favor to (100) texture formation.
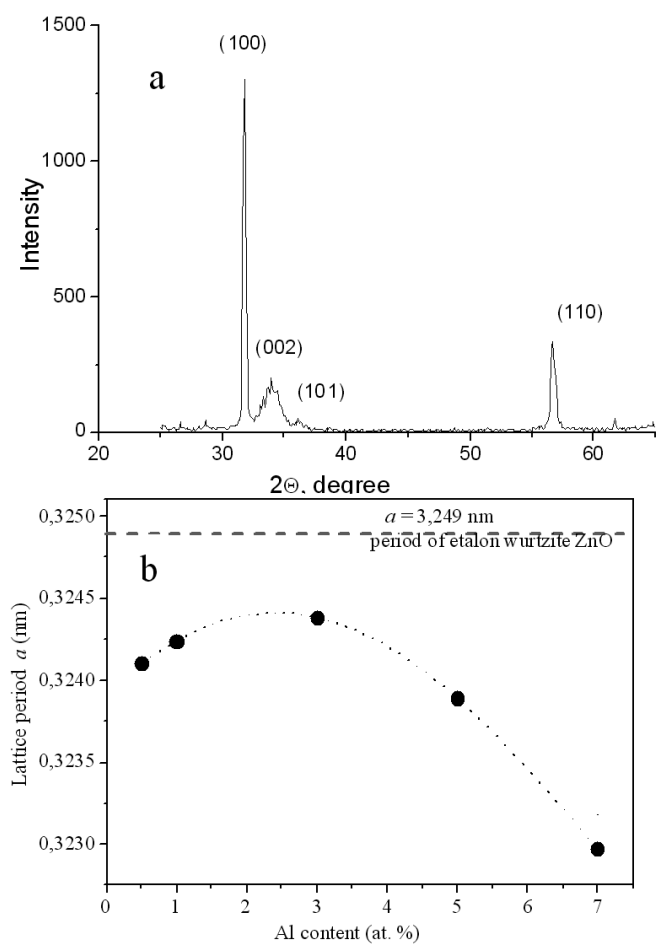

Fig. 1. XRD pattern of $\mathrm{ZnO}: \mathrm{Al}$ (3 at.\%) film (a) and $\mathrm{ZnO}$ films lattice period $a$ vs. Al content (b).

Figure $1 \mathrm{~b}$ presents the dependence of the $\mathrm{ZnO}$ film lattice period $a$ on aluminum content. We observed slight enlargement of lattice period $a$ at increase of aluminum content in $\mathrm{ZnO}$ film followed by its well-defined diminishing after $\mathrm{Al}$ content exceeds 3 at.\%. In any case, the lattice period $a$ remains below its values for undoped bulk $\mathrm{ZnO}$ crystal, indicating the presence of compressive stresses in film plane. The lattice period $a$ decreases with $\mathrm{Al}$ content because the $\mathrm{Al}^{3+}$ ionic radii is lower than substituted $\mathrm{Zn}^{2+}$ one.

The dependence of the complex dielectric permittivity, $\varepsilon=\varepsilon \prime+\mathrm{i} \varepsilon^{\prime \prime}$, on the wavelength in the spectral range of interest was approximated by using the Lorentz-Drude model

$$
\begin{aligned}
& \varepsilon^{\prime}=\varepsilon_{\mathrm{L}}-\frac{N e^{2}}{m^{*} \varepsilon_{0}}\left(\frac{\tau^{2}}{1+\omega^{2} \tau^{2}}\right), \\
& \varepsilon^{\prime \prime}=\frac{N e^{2}}{m^{*} \omega \varepsilon_{0}}\left(\frac{\tau}{1+\omega^{2} \tau^{2}}\right),
\end{aligned}
$$

where $\varepsilon_{\mathrm{L}}$ is a dielectric permittivity of lattice, $N$ - electron concentration, $m^{*}$ - effective mass, $\omega-$ angular frequency of incidence light, $\varepsilon_{0}$ - dielectric permittivity of vacuum and $\tau$ - carrier relaxation time $(\gamma=1 / \tau$ is referred as damping constant). Relaxation time $\tau$ is connected with electron mobility and effective mass by equation $\tau=m^{*} \mu / e$.

Figure 2 demonstrates experimental reflectance spectra in the range $380-1100 \mathrm{~nm}$ at several angles of the incident light and fitted spectra with permittivity according to the Lorentz-Drude model. The fitting parameters 


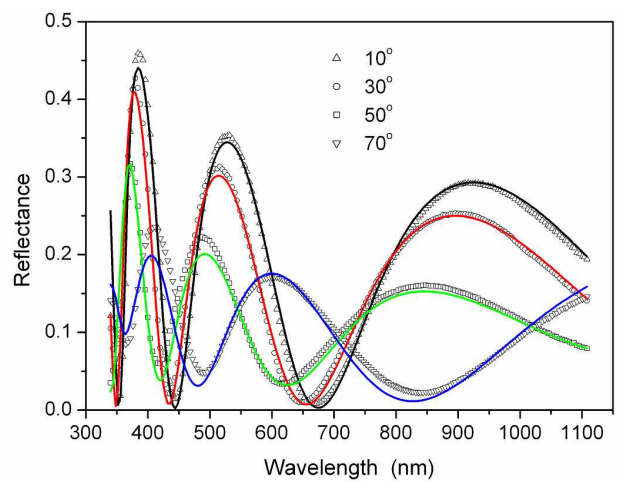

Fig. 2. Typical spectra of UV-near-IR reflectance at different angles of the light incidence for $\mathrm{ZnO}: \mathrm{Al}$ (7 at.\%) film (points - experimental data, solid lines - fitted spectra by Drude-Lorentz approximation for permittivity).

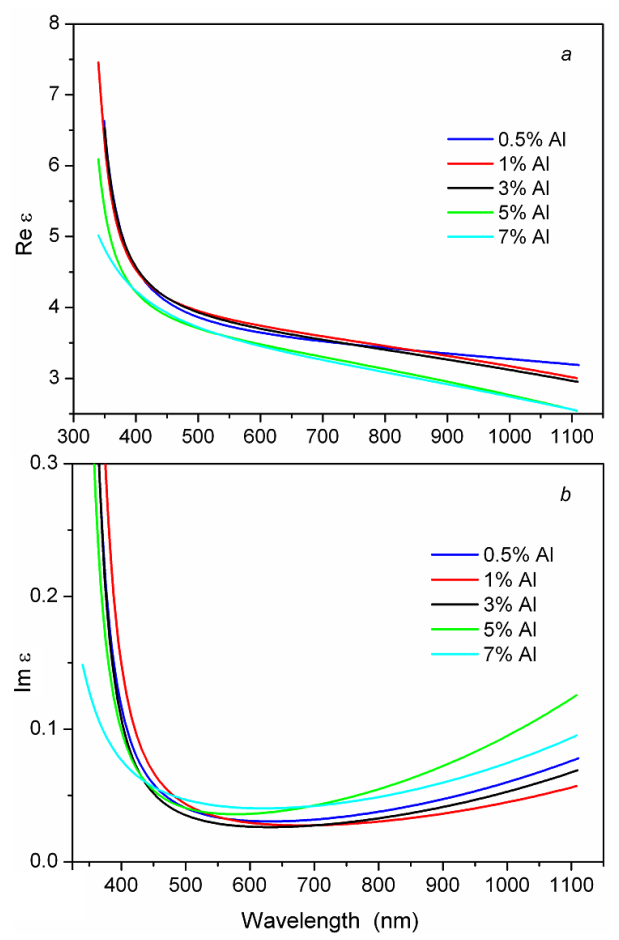

Fig. 3. Lorentz-Drude approximation of spectral dependences for Al-doped $\mathrm{ZnO}$ films permittivity in wavelength range $360-1100 \mathrm{~nm}$.

were film thickness, damping constant, and plasma frequency. Carrier concentration was known from the Hall measurements. As a result of fitting we have got two important parameters: plasma frequency $\omega_{\mathrm{p}}=$ $\left(N e^{2} / m^{*} \varepsilon_{0} \varepsilon_{\mathrm{L}}\right)^{1 / 2}$ and damping constant $\gamma$ which reflects relaxation processes and relates to optical (or in-grain) mobility. The parameters of $\mathrm{ZnO}$ :Al film obtained from fitting are collected in Table I, while spectral dependences of real and imaginary parts of permittivity are shown in Fig. 3. The film permittivities in the visible range of spectrum are the same practically for all samples with $\mathrm{Al}$ doping in the range of $0.5-3$ at.\%. But at longer wavelength the contribution of free-carrier into
$\mathrm{ZnO}$ permittivity becomes more pronounced: the higher aluminum content in $\mathrm{ZnO}$ film results in the higher imaginary part and the lower real part of $\varepsilon$.

Since plasma minima are out of spectral region for our UV-Vis-NIR spectroscopic measurements, we measured infrared reflectance spectra in the range 5000-400 $\mathrm{cm}^{1}$ with Fourier-transform spectrophotometer (Fig. 4). It is evident that minimum in reflectance is observed at $4000 \mathrm{~cm}^{-1}$ for $\mathrm{ZnO}$ films containing 0.5 at.\% of Al. The position of minima is shifted to $5800 \mathrm{~cm}^{-1}$ at increase of $\mathrm{Al}$ content in $\mathrm{ZnO}$ films. One can suggest that observed minima are connected with plasma frequency but its disposition could be changed by an interference in thin films. The analysis of obtained IR spectra with the same permittivity model gives us the more accurate values of $\omega_{\mathrm{p}}$ and $\gamma$, also presented in Table I. In addition, in the IR spectra below $1000 \mathrm{~cm}^{-1}$ there are features related to phonon modes in $\mathrm{ZnO}$. Due to small thickness of the films and high doping the $\mathrm{ZnO}$ phonon modes in the range of $400-600 \mathrm{~cm}^{-1}$ are not pronounced. We observe that the damping of $\mathrm{ZnO}$ phonons in ALD fabricated film is several times greater than for bulk $\mathrm{ZnO}$ single crystals $\left(13 \mathrm{~cm}^{-1}\right.$ vs. $\left.3 \mathrm{~cm}^{-1}\right)$. Also, in the range $600-900 \mathrm{~cm}^{-1}$ probably $\mathrm{Al}-\mathrm{O}$ vibration mode arises in IR spectra for $\mathrm{ZnO}$ films with 5 and 7 at.\% of $\mathrm{Al}$.

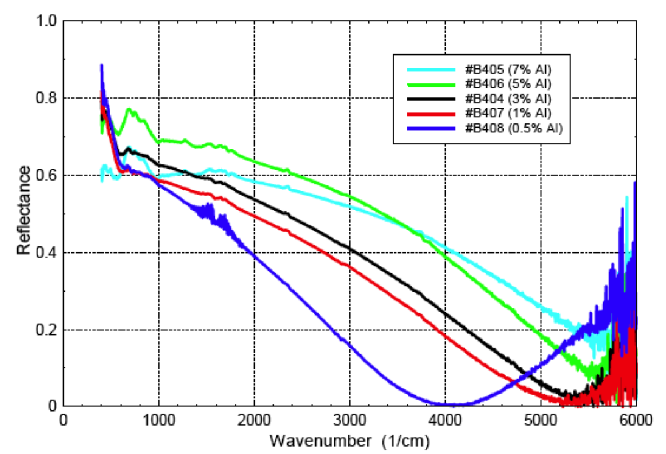

Fig. 4. IR reflectance spectra for $\mathrm{ZnO}$ films on $\mathrm{Si}$ substrates at various $\mathrm{Al}$ concentrations.

From the data of optical spectroscopy presented in Table I we can see that visible spectroscopy gives us significantly higher values $\omega_{\mathrm{p}}$ compared with ones from IR spectroscopy. This can be explained by enhanced electron interaction with infrared radiation. Thus, results for $\omega_{\mathrm{p}}$ obtained from IR reflection are more realistic. Damping constant $\gamma$ increases with increasing aluminum content in films indicating increased light scattering on free electrons whose concentration also increases with doping. Using optical data as well as the carrier concentration obtained from standard Hall measurements we can determine electron effective mass $m^{*}$ from plasma frequency $\omega_{\mathrm{p}}$, as well as optical mobility from equation $\mu_{\mathrm{opt}}=e /\left(\gamma m^{*}\right)$. The electrical resistivity, electron concentration and Hall mobility as well as optical mobility and electron effective mass calculated from optical data are presented in Table II. 
TABLE I

Film optical parameters calculated from visible and infrared reflectance spectra for $\mathrm{ZnO}: \mathrm{Al}$ films.

\begin{tabular}{c|c|c|c|c|c|c}
\hline \hline \multirow{2}{*}{$\begin{array}{c}\text { Al } \\
\text { content }\end{array}$} & $\begin{array}{c}\text { Thickness } \\
{[\mathrm{nm}]}\end{array}$ & \multicolumn{2}{|c|}{ Visible spectroscopy } & \multicolumn{3}{|c}{ Infrared spectroscopy } \\
\cline { 3 - 7 } [at.\%] & $\begin{array}{c}\text { Plasma } \\
\text { frequency } \\
\omega_{\mathrm{p}},\left[\mathrm{cm}^{-1}\right]\end{array}$ & $\begin{array}{c}\text { Damping } \\
\text { constant } \\
\gamma\left[\mathrm{cm}^{-1}\right]\end{array}$ & $\begin{array}{c}\text { Plasma } \\
\text { frequency } \\
\omega_{\mathrm{p}},\left[\mathrm{cm}^{-1}\right]\end{array}$ & $\begin{array}{c}\text { Damping } \\
\text { constant } \\
\gamma,\left[\mathrm{cm}^{-1}\right]\end{array}$ & $\begin{array}{c}\text { High freq. } \\
\text { dielectric } \\
\text { constant } \varepsilon_{\infty}\end{array}$ \\
\hline 0.5 & 420 & 3327 & 1691 & $2380 \pm 100$ & $995 \pm 100$ & 3.88 \\
1 & 285 & 4529 & 851 & $3027 \pm 80$ & $967 \pm 50$ & 3.66 \\
3 & 320 & 4500 & 845 & $3579 \pm 50$ & $1261 \pm 40$ & 3.32 \\
5 & 330 & 5421 & 944 & $4635 \pm 90$ & $1515 \pm 100$ & 3.42 \\
7 & 260 & 6439 & 786 & $4985 \pm 100$ & $1900 \pm 50$ & 2.92
\end{tabular}

TABLE II

Electrical and optical parameters for Al-doped $\mathrm{ZnO}$ films derived from electrical and Hall measurements as well as IR optical investigations.

\begin{tabular}{|c|c|c|c|c|c|c|c|}
\hline \multirow[b]{2}{*}{$\begin{array}{c}\mathrm{Al} \\
\text { content } \\
\text { [at.\%] }\end{array}$} & \multicolumn{3}{|c|}{ Electrical measurements } & \multicolumn{2}{|c|}{ Optical measurements } & \multirow{2}{*}{$\begin{array}{c}\text { Carriers } \\
\text { trap } \\
\text { density } \\
N_{\mathrm{t}} \\
{\left[\times 10^{13} \mathrm{~cm}^{-2}\right]}\end{array}$} & \multirow[b]{2}{*}{$\mu_{\mathrm{opt}} / \mu$} \\
\hline & $\begin{array}{c}\text { Resistivity } \\
\rho \\
{\left[\times 10^{-3} \Omega \mathrm{cm}\right]}\end{array}$ & $\begin{array}{c}\text { Electron } \\
\text { concentra- } \\
\text { tion } N \\
{\left[\times 10^{20} \mathrm{~cm}^{-3}\right]}\end{array}$ & $\begin{array}{c}\text { Electron } \\
\text { mobility } \\
\mu \\
{\left[\mathrm{cm}^{2} /(\mathrm{V} \mathrm{s})\right]}\end{array}$ & $\begin{array}{c}\text { Electron } \\
\text { mobility } \\
\mu_{\mathrm{opt}} \\
{\left[\mathrm{cm}^{2} /(\mathrm{V} \mathrm{s})\right]}\end{array}$ & 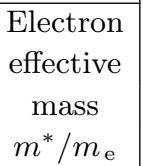 & & \\
\hline 0.5 & 4.21 & 0.92 & 16.2 & 25.1 & 0.373 & 1.77 & 1.55 \\
\hline 1 & 4.13 & 1.09 & 13.9 & 33.2 & 0.291 & 2.01 & 2.38 \\
\hline 3 & 2.84 & 1.98 & 11.1 & 17.8 & 0.417 & 2.74 & 1.60 \\
\hline 5 & 2.00 & 3.62 & 8.6 & 14.0 & 0.441 & 3.82 & 1.63 \\
\hline 7 & 2.52 & 4.01 & 6.2 & 9.9 & 0.494 & 4.15 & 1.61 \\
\hline
\end{tabular}

Comparing the amount of introduced aluminum with obtained electron concentration we can state that there is a large amount of non-electroactive aluminum in our films. At low doping level there is approximately $46 \%$ of electro-active aluminum. This value drops down to $14 \%$ with increasing $\mathrm{Al}$ content up to 7 at.\%. This fact obviously suggests that there are factors preventing effective aluminum doping of $\mathrm{ZnO}$. One is the oxidizing of aluminum at film growth, another is segregation of $\mathrm{Al}$ on grain boundaries and third one is a formation of nonelectroactive centers, for example $\mathrm{Al}_{Z n}-\mathrm{O}_{i}, \mathrm{Al}_{Z n}-\mathrm{V}_{Z n}$ which are deep acceptor complexes or neutral complex of $2 \mathrm{Al}_{Z n}-\mathrm{V}_{Z n}$ [12]. All these factors influence on electrical properties of films and can explain why as $\mathrm{Al}$ content increased 7 times (from 1 at.\% to 7 at.\%) the carrier concentration increased only 4 times and mobility reduced to half approximately. In polycrystalline films the carrier transport across the grain barriers can be described in terms of thermionic emission which gives the following expression for effective mobility: $\mu_{\mathrm{eff}}=\mu_{0} \exp \left(-\varphi_{\mathrm{b}} / k T\right)$, where $\varphi_{\mathrm{b}}$ is the height of the energetic barriers between grains and prefactor $\mu_{0}=e L /\left(2 \pi m^{*} k T\right)^{1 / 2}$, where $L$ is the grain size. Barrier's height $\varphi_{\mathrm{b}}$ depends on doping concentration and on boundary located carrier trap density $N_{\mathrm{t}}$ as following: $\varphi_{\mathrm{b}}=e^{2} N_{\mathrm{t}}^{2} /\left(8 \varepsilon \varepsilon_{0} N\right)$ [13]. Taking into account that average grains size $L$ does not change with carrier concentrations (accordingly to AFM investigations $L \approx 30 \mathrm{~nm}$ ) we can estimate density of carriers traps applying $\varepsilon=8.85$ (see Table II). Noticeably, in the given carrier concentration range optical mobility 1.6 times exceeds Hall mobility. This means that grain boundary scattering is meaningful. However, decrease of mobility with increase of carrier concentration testifies that scattering on ionized impurities as well as on mentioned complexes occurs.

Another reason for decrease of the mobility with increase of carrier concentration is the influence of nonparabolicity of $\mathrm{ZnO}$ band gap. Electron effective mass as a function of electron concentration is pictured in Fig. 5. The right axis describes the electron effective mass relative to electron effective mass on the bottom of conduction band $\left(m_{0}^{*}\right)$ and the top axis describes the electron energy relative to bottom of conduction band $E_{\mathrm{c}}$ calculated accordingly to the Elmer equation [6]. In the given coordinates the non-parabolicity parameter $C\left(C \sim 1 / E_{\mathrm{g}}\right)$ can be easily calculated in accordance with the following expression: $m^{*} / m_{0}^{*}=1+2 C\left(E-E_{\mathrm{c}}\right)$. We found that $C$ equals $0.33 \mathrm{eV}^{-1}$ at $m_{0}^{*}=0.24 m_{\mathrm{e}}$. In the case of lattice scattering or ionized impurity scattering, the mobility is proportional reciprocally to square of electron effective mass, thus non-parabolicity of band gap diminishes electron mobility. 


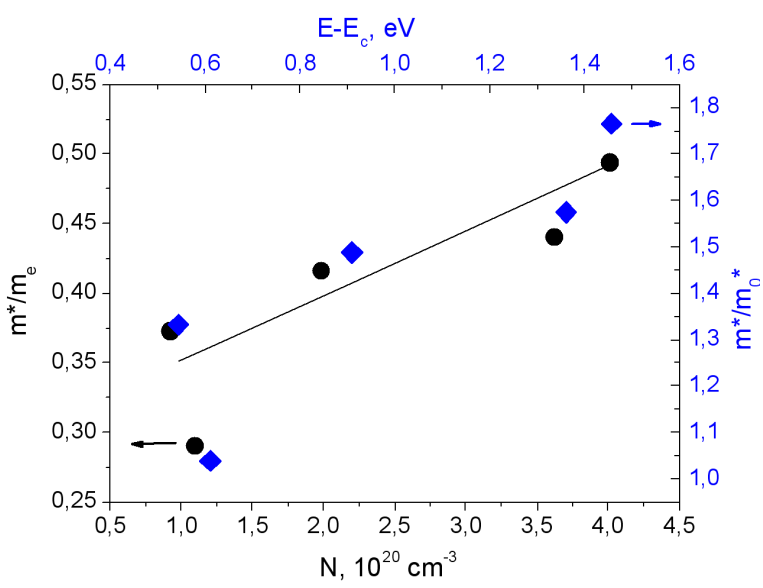

Fig. 5. Dependence of electron effective mass on electron concentration. The $E-E_{\mathrm{c}}$ values were calculated in accordance with expression proposed by Ellmer.

\section{Conclusion}

We have investigated structure, optical and electrical properties of $\mathrm{ZnO}: \mathrm{Al}$ films deposited by ALD technology. XRD patterns of $\mathrm{ZnO}$ doped by $0.5-7 \% \mathrm{Al}$ show that preferred crystallite orientation is (100). According to electrical and Hall measurements the carrier concentration, mobility and resistivity were in the ranges $(0.9-4) \times$ $10^{20} \mathrm{~cm}^{-3}, 16-6 \mathrm{~cm}^{2} /(\mathrm{V} \mathrm{s}),(4.2-2.5) \times 10^{-3} \Omega \mathrm{cm}$, respectively. Reflectance dependences were described in terms of the Lorentz-Drude theory. At increasing carrier concentration plasma frequency $\omega_{\mathrm{p}}$ increases from $2380 \mathrm{~cm}^{-1}$ for $\mathrm{ZnO}$ with 0.5 at.\% of $\mathrm{Al}$ to $4985 \mathrm{~cm}^{-1}$ for $\mathrm{ZnO}$ with 7 at.\% of $\mathrm{Al}$. At the same time damping parameter $\gamma_{\mathrm{p}}$ also increases from 995 to $1900 \mathrm{~cm}^{-1}$ testifying to an enhanced light scattering due to absorption by free electrons. The electron effective mass increases from 0.37 to $0.49 m_{0}$ at the electron concentration increasing from $0.92 \times 10^{20}$ to $4 \times 10^{20} \mathrm{~cm}^{-3}$. The dependence of electron mass on electron concentration is due to a non-parabolicity of the conduction band. Comparison of optical and Hall mobilities testifies to a contribution of scattering on grain boundaries about $60 \%$. Taking into account a large amount of non-electroactive $\mathrm{Al}$ in films as well as dependences of optical mobility on doping we suggest that scattering occurs on ionized impurities.

\section{Acknowledgments}

This work was partially supported by the National Science Centre (decision No. DEC-2012/06/A/ST7/00398).

\section{References}

[1] T. Minami, Thin Solid Films 516, 5822 (2008).

[2] K. Elmer, T. Welzel, J. Mater. Res. 27, 765 (2012).

[3] H. Yoshikawa, S. Adachi, Jpn. J. Appl. Phys. 36, 6237 (1997)

[4] P.L. Washington, H.C. Ong, J.Y. Dai, R.P.H. Chang, Appl. Phys. Lett. 72, 3261 (1998).

[5] A. Abdolahzadeh Ziabari, S.M. Rozati, Physica B 407, 4512 (2012).

[6] K. Ellmer, J. Phys. D Appl. Phys. 34, 3097 (2001).

[7] F. Ruske, A. Pflug, V. Sittinger, B. Szyszka, D. Greiner, B. Rech, Thin Solid Films 518, 1289 (2009).

[8] J. Tang, L.Y. Deng, C.B. Tay, X.H. Zhang, J.W. Chai, H. Qin, H.W. Liu, T. Venkatesan, S.J. Chua, J. Appl. Phys. 115, 033111 (2014).

[9] T. Yamada, H. Makino, N. Yamamoto, T. Yamamoto, J. Appl. Phys. 107, 123534 (2010).

[10] Y. Kajikawa, J. Cryst. Growth 289, 387 (2006).

[11] A. Wojcik, M. Godlewski, E. Guziewicz, R. Minikayev, W. Paszkowicz, J. Cryst. Growth 310, 284 (2008).

[12] J.T. Thienprasert, S. Rujiravat, W. Klysubun, J.N. Duenow, T.J. Coutts, S.B. Zhang, D.C. Look, S. Limpijumnong, Phys. Rev. Lett. 110, 055502 (2013).

[13] K. Ellmer, A. Klein, B. Rech, Transparent Conductive Zinc Oxide: Basics and Applications in Thin Film Solar Cells, Vol. 104, Springer Science and Business Media, Berlin Heidelberg 2007, p. 60. 